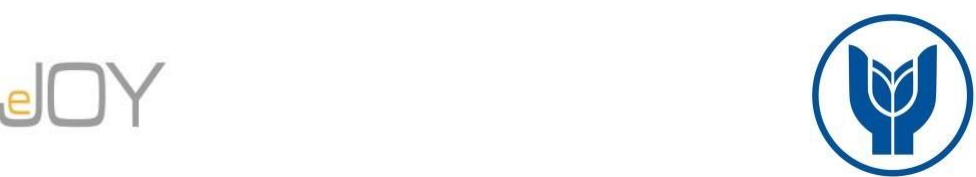

Arsu, T., Ayçin, E. / Journal of Yasar University, 2021, 16/63, 1282-1300

\title{
Üçüncü Parti Tersine Lojistik Servis Sağlayıcısı Seçimi Kriterlerinin Bulanık SWARA Yöntemi ile Değerlendirilmesi
}

\section{Evaluation of Third-Party Reverse Logistics Service Provider Selection Criteria with Fuzzy SWARA Method}

\author{
Talip ARSU, Aksaray Üniversitesi, Türkiye, taliparsu@aksaray.edu.tr \\ Orcid No: 0000-0002-2580-166X \\ Ejder AYÇİN, Kocaeli Üniversitesi, Türkiye, ejder.aycin@kocaeli.edu.tr \\ Orcid No: 0000-0002-0153-8430
}

\begin{abstract}
Öz: Tersine lojistik, iş faaliyetlerinin çevresel ve sosyal yönlerinin sürdürülebilir kalkınmanın anahtarı olduğu günümüzde, işletmelerin rekabetçi kalabilmeleri ve kendilerine ekonomik fayda sağlayabilmeleri için oldukça önemli bir hale gelmiştir. Tersine lojistik sistemlerinin operasyonlart ve yönetimi, önemli düzeyde altyapl, teknoloji, uzmanlık ve deneyim gerektiren karmaşık bir görevdir. Bu nedenle, çok saylda işletme tersine lojistik faaliyetlerini üçüncü parti tersine lojistik servis sağlayıcılarına (3PTLS) devretme eğilimindedir. Bu noktadan hareketle bu çalışmanın amacı 3PTLS seçiminde dikkate alınacak kriterlerinin bulanık SWARA yöntemi ile değerlendirilmesi olarak belirlenmiştir. Bu doğrultuda kapsamlı bir literatür taramasının ardından, uzman bir grubun görüşü alınarak kriterler değerlendirilmiştir. Uygulama sonucunda en önemli kriterler sırasıyla müşteri memnuniyeti, çevre bilinci ve hizmet kalitesi en önemsiz kriterler ise bertaraf, geri çă̆ırma ve sipariş yönetimi olarak belirlenmiştir.
\end{abstract}

Anahtar Kelimeler: Tersine Lojistik, Üçüncü Parti Tersine Lojistik Servis Sağlayıcısı (3PTLS), Bulanık SWARA

JEL Sinıflandirması: M11, C61, Q53

\begin{abstract}
Reverse logistics has become especially important for businesses to remain competitive and to provide economic benefits to them in today's world, where environmental and social aspects of business activities are the key to sustainable development. Operations and management of reverse logistics systems is a complex task that requires significant infrastructure, technology, expertise, and experience. For this reason, many businesses tend to outsource their reverse logistics activities to third party reverse logistics service providers (3PRLP). From this point of view, the aim of this study is to evaluate the criteria to be considered in 3PTLS selection using the fuzzy SWARA method. Accordingly, after a comprehensive literature review, the criteria were evaluated by taking the opinion of an expert group. As a result of the implementation, the most important criteria were determined as customer satisfaction, environmental awareness and service quality, the least important criteria were disposal, recall and order management.
\end{abstract}

Keywords: Reverse Logistics, Third Party Reverse Logistics Provider (3PRLP), Fuzzy SWARA

JEL Classification: M11, C61, Q53

\section{Giriş}

Üretim kaynaklarının tüm üreticiler için ulaşılabilir hale gelmesi, üretilen ürünler için benimsenen sıkı kalite standartları, Ar-Ge faaliyetlerinin tüm üretim işletmeleri arasında yaygınlaşması gibi sebepler rekabet faktörünü üretilen üründen değer zincirindeki diğer fonksiyonlara kaydırmıştır. Değer zincirinde salt üretim faaliyeti dışında diğer tüm faaliyetlerde lojistik süreçler bulunmaktadır. Bu da lojistik süreçlerin, işletmelerin değer zincirindeki en temel rekabet faktörü olarak benimsenmesine yol açmıştır. Fakat, çevresel endişeler ile kullanım ömrünü tamamlamış ürünlerin yeniden ekonomiye kazandırılarak maliyet avantajı 
sağlanması fikri lojistik faaliyetlerin genişletilmesini zorunlu kılmıştır. Bu zorunluluk sonucu ortaya çıkan faaliyetlere ilk zamanlar tersine dağıtım, tersine akış, tersine kanallar gibi isimler verilmiştir (Zikmund ve Stanton, 1971; Guiltinan ve Nwokoye, 1975; Ginter ve Starling, 1978). Tersine lojistik adı ise ilk olarak 1982 yılında Lambert ve Stock tarafından kullanılmıştır (Rogers ve Tibben-Lembke, 2001:129). Tersine lojistik kullanım süresi dolmuş ürünlerin nihai tüketicilerden hammadde tedarikçilerine doğru tersine akışı temeline dayanmaktadır.

Üretim ölçeğinin küçük olduğu ve dağıtım kanallarının karmaşık olmadığı zamanlarda işletmeler lojistik faaliyetlerini kendi alt yapısı ile gerçekleştirmiştir. Fakat zamanla işletmelerin lojistik faaliyetlere harcadığı eforu temel faaliyet alanlarına kaydırma isteği ve lojistik faaliyetlerin alanında uzman işletmeler tarafından yapılması düşüncesi lojistik servis sağlayıcılarının ortaya çıkmasına sebep olmuştur. Lojistik servis sağlayıcılar uzun yıllar boyunca işletmelerin lojistik faaliyetlerinde kullandığı partnerleri olarak hizmet vermiştir. Bununla birlikte hem lojistik servis sağlayıcılar hem de kendi lojistik alt yapısını kullanan işletmeler lojistik faaliyetlerde gösterdiği başarıyı tersine lojistik faaliyetinde yakalayamayabilir. Çünkü tersine lojistik faaliyeti klasik ileriye doğru lojistik faaliyetlerinden farkl1 yeterlilik ve kaynak gerektirmektedir (Zhang ve Feng, 2007: 479). Bu ihtiyaç tersine lojistik faaliyetleri konusunda uzman ve gerekli teknik bilgiye sahip üçüncü parti tersine lojistik servis sağlayıcıların (3PTLS) yaygınlaşmasına temel hazırlamıştır. 3PTLS'lerin yaygınlaşması ile karmaşık ağları yönetmek için kaynak veya kabiliyete sahip olmayan birçok işletme, verimli bir tersine lojistik süreci sağlamak için tersine lojistik faaliyetlerinin tamamını veya bir kısmını 3PTLS'lere bırakmıştır (Cheng ve Lee, 2010: 1112). Geleneksel olarak 3PTLS'ler kullanım ömrü dolmuş ürünü toplar, kategorilerine ayırır, muayenesini yapar daha sonra durumuna ve kalitesine göre gerekli tersine lojistik sürecine sokarak satar. Fakat son ylllarda özellikle üretim işletmeleri ile 3PTLS'ler etkili iletişim ve iş birliğine dayalı ilişkiler kurmaktadır. Artık üretim işletmeleri ile 3PTLS'lerin ortak amaçları klasik tersine lojistik geri kazanım yöntemlerini uygulamanın yanında maksimum fayda sağlamak ve ulaştırma/ işletme maliyetlerini en aza indirmektir (Govindan vd., 2019: 608). Bu açıdan işletmeler için hizmet alımı yapılan bir hizmet tedarikçisi olmanın yanında bir partner haline gelen 3PTLS'lerin seçimi hayati bir önem kazanmıştır. İşletmeler için 3PTLS'lerin seçim sürecinde kullanılan farklı türde birçok yöntem bulunmaktadır. Fakat çeşitli boyutları ve çeşitli kriterleri aynı anda dikkate alarak değerlendiren Çok Kriterli Karar Verme (ÇKKV) yöntemleri bu seçim süreci için en fazla kullanılan yöntemlerin başında gelmektedir (Zarbakhshnia vd., 2020: 2). Bununla birlikte seçim sürecinden önce işletmeler veya 3PTLS seçim sürecini araştırma konusu yapan bilim insanları seçim sürecinde kullanacağı kriterleri belirlemelidir. Çünkü doğru 3PTLS'nin seçimi ancak 
doğru kriterlerin kullanılması ile mümkündür. Bu noktadan hareketle bu çalışmanın amacı literatürde yer alan 3PTLS seçim kriterlerinin bulanık SWARA (A Step-wise Weight Assessment Ratio Analysis) yöntemi ile değerlendirilmesi olarak belirlenmiştir. Bu amaçla öncelikle literatürde yer alan 3PTLS seçim kriterleri belirlenmiştir. Daha sonra bu seçim kriterleri hakkında alınan uzmanların görüşleri, bulanık SWARA yöntemi ile çözülüp kriterlerin önem sıraları belirlenmiştir.

\section{Literatür Taraması}

Literatür incelendiğinde 3PTLS seçiminin birçok akademik çalışmaya konu olduğu görülmüştür. Genellikle çalışmalar 3PTLS için kriter seçerken ya mevcut literatürü dikkate almış ya da uzman görüşlerine ihtiyaç duymuştur. Bu çalışmalardan bir kısmı sadece kriter seçimine odaklanırken bir kısmı ise hem kriterlerin değerlendirilmesi hem de 3PTLS'lerin seçimi üzerine odaklanmıştır. Bu çalışmada kullanılan bulanık SWARA yöntemi bir ÇKKV yöntemi olduğundan dolayı değerlendirilecek kriterler belirlenirken 3PTLS seçiminde ÇKKV yöntemleri kullanan çalışmalar dikkate alınmıştır. Bu çalışmalarda kullanılan yöntemler ile kullanılan kriterler Tablo 1'de özetlenmiştir. 
Tablo 1. 3PTLS Seçiminde Kullanılan ÇKKV Yöntemleri ve Kriterler

\begin{tabular}{|c|c|c|c|}
\hline Yazar & Yöntem & Kriterler & Alt- Kriterler \\
\hline \multirow{4}{*}{$\begin{array}{l}\text { Meade ve Sarkis } \\
(2002)\end{array}$} & \multirow{4}{*}{ ANP } & Ürün yaşam döngüsü aşamaları & Sunuş, gelişim, olgunluk, çöküş \\
\hline & & Örgüt performansı kriterleri & Zaman, kalite, maliyet, esneklik \\
\hline & & $\begin{array}{l}\text { Tersine lojistik süreci } \\
\text { fonksiyonları }\end{array}$ & Toplama, paketleme, depolama, ayırma, geçiş süreci, teslim \\
\hline & & $\begin{array}{l}\text { Tersine lojistiğin } \\
\text { organizasyondaki rolü }\end{array}$ & Geri çağırma, geri dönüşüm, yeniden üretim, yeniden kullanım, geri alım, bertaraf \\
\hline \multirow{5}{*}{$\begin{array}{l}\text { Zhang ve Feng } \\
(2007)\end{array}$} & \multirow{5}{*}{ Bulanık AHP } & Yetenekler & $\begin{array}{l}\text { Finansal yatırım yeteneği, bilgi izleme teknolojisi, nakliye kapasitesi, ağ kapsamı, } \\
\text { ekipman servis kapasitesi }\end{array}$ \\
\hline & & Ortaklık & $\begin{array}{l}\text { İşbirliğinin tarihi, paylaşılan fayda ve riskler, temel yeterlilikler, stratejik uyumluluk } \\
\text { kavramı }\end{array}$ \\
\hline & & Hizmetler & Hizmet kalitesi, müşteri memnuniyeti \\
\hline & & Deneyimler & Hizmet süresi, hizmet sağlama türü \\
\hline & & \multicolumn{2}{|c|}{ Fiyat } \\
\hline Efendigil vd. (2008) & Bulanık AHP & \multicolumn{2}{|c|}{$\begin{array}{l}\text { Zamanında teslim oranı, onaylanmış doluluk oranı, hizmet kalite düzeyi, birim operasyon maliyeti, kapasite kullanım } \\
\text { oranı, toplam sipariş çevrim süresi, sistem esneklik indeksi, etkileşim düzeyi indeksi, pazar payındaki artış, Ar\&Ge oranı, } \\
\text { çevresel harcamalar, müşteri memnuniyet indeksi }\end{array}$} \\
\hline Saen (2009) & VZA & \multicolumn{2}{|c|}{$\begin{array}{l}\text { Gönderilerin toplam maliyeti (girdi), 3. parti servis sağlayıcısının itibarı (girdi), 3. parti servis sağlayıcısından alınan } \\
\text { hatasız faturaların sayısı (çıktı) }\end{array}$} \\
\hline Kannan vd. (2009) & Bulanık TOPSIS & \multicolumn{2}{|c|}{$\begin{array}{l}\text { Kalite, teslimat, tersine lojistik maliyeti, reddedilme oranı, teknik/mühendislik kapasitesi, gelecekteki gereksinimi } \\
\text { karş1layamama, isteklilik ve tutum }\end{array}$} \\
\hline \multirow{4}{*}{ Cheng ve Lee (2010) } & \multirow{4}{*}{ ANP } & Depo yönetimi & Çapraz yükleme, sipariş hazırlama, müşteri-özel etiketinin yazdırılması, depolama \\
\hline & & Nakliye yönetimi & Filo yönetimi, navlun sevkiyat1 \\
\hline & & Bilgi teknolojileri yönetimi & $\begin{array}{l}\text { Bilgi sistemi yönetimi, takip ve izleme, web tabanlı bağlantı, gelişmiş yükleme } \\
\text { bildirimi }\end{array}$ \\
\hline & & Katma değerli hizmetler & $\begin{array}{l}\text { Montaj/demontaj, yeniden paketleme/yeniden etiketleme, yeniden üretim, yenileme, } \\
\text { bertaraf }\end{array}$ \\
\hline Saen (2010) & VZA & \multicolumn{2}{|c|}{$\begin{array}{l}\text { Toplam gönderi maliyeti (I), Geri dönüştürülebilir ürünlerin satışından elde edilen gelir (O), Hizmet kalitesi deneyimi (I- } \\
\text { O), Hizmet kalitesi güvenilirliği (I-O) }\end{array}$} \\
\hline $\begin{array}{l}\text { Sasikumar ve Haq } \\
\text { (2011) }\end{array}$ & $\begin{array}{l}\text { Bulanık VIKOR, } \\
\text { Tamsayılı } \\
\text { Programlama }\end{array}$ & \multicolumn{2}{|c|}{$\begin{array}{l}\text { Toplam maliyet, satın alma maliyeti, üretim maliyeti, nakliye maliyeti, geri dönüşüm/geri çağırma maliyeti, bertaraf } \\
\text { maliyet, toplama maliyeti }\end{array}$} \\
\hline \multirow{3}{*}{ Govindan vd. (2013) } & \multirow{3}{*}{ ANP } & Yeterlilikler & $\begin{array}{l}\text { Kalite yönetimi, hizmet maliyeti, hizmet zamanı, esneklik, belirsizlik altındaki } \\
\text { yetenekler }\end{array}$ \\
\hline & & Operasyonel performans & Geri alım politikası, paketleme, depolama, ayırma, geçiş süreci, teslim \\
\hline & & Örgütsel rol & Geri çağırma, geri dönüşüm, yeniden üretim, yeniden kullanım, bertaraf \\
\hline
\end{tabular}




\begin{tabular}{|c|c|c|c|}
\hline & & Teknolojik yenilikler & $\begin{array}{l}\text { Depo yönetimi, nakliye yönetimi, stok yönetimi, tam zamanında üretim felsefesi, bilgi } \\
\text { teknolojisi, talep tahmini }\end{array}$ \\
\hline & & Risk yönetimi & $\begin{array}{l}\text { Şikâyet yönetimi, sipariş yönetimi, tedarik zinciri planlaması, sevkiyat ve takip, } \\
\text { navlun ödeme }\end{array}$ \\
\hline & & Finansal performans & Pazar pay1, karlılık, varlıklar, itibar \\
\hline & & Kullanıcı memnuniyeti & Etkili iletişim, hizmet geliştirme, tüm iş ilişkileri \\
\hline & & Coğrafi dağılım & \\
\hline & & A $\breve{g}$ boyutu & \\
\hline \multirow{9}{*}{ Senthil vd. (2014) } & \multirow{9}{*}{ AHP-TOPSIS } & Örgütsel performans kriteri & Zaman, maliyet, esneklik \\
\hline & & $\begin{array}{l}\text { Tersine lojistik süreci } \\
\text { fonksiyonları }\end{array}$ & Toplama, paketleme, depolama, ayırma, geçiş süreci, teslimat \\
\hline & & Tersine lojistiğin örgütsel rolü & Geri çağırma, geri dönüşüm, yeniden üretim, yeniden kullanım, geri alım, bertaraf \\
\hline & & Kaynak kapasitesi & Finansal yatırım kapasitesi, gelişmiş ekipman düzeyi, ağ kapasitesi, nakliye kapasitesi \\
\hline & & Hizmet kalitesi & Zamanında hizmet verme, kişiselleştirilmiş hizmet, sorunlarla başa çıkma yeteneği \\
\hline & & Kurumsal İttifak & Fayda ve risklerin paylaşımı, kurumsal kültür uyumluluğu \\
\hline & & Konum & Bölgeye aşina olma, coğrafi konum, kültürel uyum, insan kaynakları \\
\hline & & Deneyim & Performans geçmişi \\
\hline & & İletişim sistemleri & Elektronik veri değişimi (EDI) kapasitesi, bilgi teknolojileri düzeyi \\
\hline \multirow{4}{*}{ Hsueh ve Lin (2015) } & \multirow{4}{*}{ ANP } & Faydalar & $\begin{array}{l}\text { Rekabet avantaj1, kurumsal imaj, geri dönüştürülmüş malzemeler kullanarak üretim } \\
\text { maliyetini düşürme, ekonomik/ finansal faydalar, enerji tasarrufu }\end{array}$ \\
\hline & & Firsatlar & Hükümet politikası, çevre bilinci, yaşam kalitesi \\
\hline & & Maliyetler & $\begin{array}{l}\text { Nakliye maliyeti, ekipman ve bina maliyeti, işçilik maliyeti, bakım maliyeti, firsat } \\
\text { maliyeti, sosyal sorumluluk, geri dönüşüm eğitim ve tanıtım maliyeti }\end{array}$ \\
\hline & & Riskler & $\begin{array}{l}\text { Müşteri riski, finansal risk, dahili iş süreci riski, öğrenme ve yenilik riski, mevzuat / } \\
\text { siyasi risk }\end{array}$ \\
\hline \multirow{7}{*}{$\begin{array}{l}\text { Prakash ve Barua } \\
(2016 a)\end{array}$} & \multirow{7}{*}{$\begin{array}{l}\text { Bulanık AHP- } \\
\text { VIKOR }\end{array}$} & Firma performans1 & Zaman, esneklik kapasitesi, kolaylık \\
\hline & & Kaynak kapasitesi & Yatırım kapasitesi, gelişmiş bileşen ve ekipmanlar, depolama \\
\hline & & Teslimat hizmeti & Hizmet düzeyi, özelleştirilmiş hizmet, problem çözme yeteneği \\
\hline & & Tersine lojistik operasyonları & $\begin{array}{l}\text { Toplama, ayırma, depolama, ara süreç, nakliye, tamir, geri dönüşüm, yeniden üretim, } \\
\text { bertaraf }\end{array}$ \\
\hline & & $\begin{array}{l}\text { İletişim ve bilgi teknolojileri } \\
\text { sistemi }\end{array}$ & Entegre sistem, paylaş1lan iletişim, etkin RFID/EDI sistemi, bilgi güvenlik sistemi \\
\hline & & Coğrafi konum & Varış yeri ve pazar kapsamı, sevkiyat, dağıtım \\
\hline & & İtibar ve Deneyim & İmaj, paylaşılan fayda ve riskler, yapı, kültür \\
\hline \multirow{3}{*}{$\begin{array}{l}\text { Prakash ve Barua } \\
(2016 b)\end{array}$} & \multirow{3}{*}{$\begin{array}{l}\text { Bulanık AHP- } \\
\text { Bulanık VIKOR }\end{array}$} & Kapasite Kriteri & Zaman, esneklik kapasitesi, elverişlilik, depo \& tamir merkezi kapasitesi \\
\hline & & Finansal yetenekler & Tesis, süreç, lojistik maliyetler, yatırım kapasitesi, gelişmiş bileşen ve ekipmanlar \\
\hline & & Bilgi teknolojileri Sistemi & Entegre sistem, paylaşılan iletişim, etkin RFID/EDI sistemi, bilgi güvenlik sistemi \\
\hline
\end{tabular}




\begin{tabular}{|c|c|c|c|}
\hline & & Hizmet kalitesi & $\begin{array}{l}\text { Hizmet düzeyi, özelleştirilmiş hizmet, problem çözme yeteneği, kişiselleştirme, } \\
\text { yetenekler }\end{array}$ \\
\hline & & Tersine lojistik aktiviteleri & $\begin{array}{l}\text { Toplama, ayırma, depolama, ara süreç, nakliye, yenileme, geri dönüşüm, yeniden } \\
\text { üretim, bertaraf }\end{array}$ \\
\hline & & Coğrafi konum & Varış yeri ve pazar kapsamı, sevkiyat, dağıtım \& teslimat \\
\hline & & Partner imaj ve deneyimi & Paylaşılan fayda ve riskler, yapı, kültür, yetkinlik, uyumluluk ve iş birliği \\
\hline \multirow{8}{*}{ Tavana vd. (2016) } & \multirow{8}{*}{ ANP } & Tesisler & Depolama \\
\hline & & Tesisler/kaynaklar & Lojistik hizmetinde depo yönetimi, bilgi teknolojilerinde depo yönetimi \\
\hline & & Stok & Stok yenileme \\
\hline & & Stok/bilgi/fiyatlama & Sunuş, gelişme, olgunluk \\
\hline & & Taşıma & $\begin{array}{l}\text { Toplama, doğrudan taşıma hizmetleri, sevkiyat ve izleme, geçiş süreci, teslimat, } \\
\text { yükleme konsolidasyonu }\end{array}$ \\
\hline & & Bilgi & $\begin{array}{l}\text { Kalite, zaman, esneklik, müşteri memnuniyeti, çalışan morali, bilgi teknolojileri } \\
\text { kullanarak tedarik zinciri planlaması, etkili iletişim, hizmet geliştirme, tüm iş ilişkileri }\end{array}$ \\
\hline & & Kaynaklar & $\begin{array}{l}\text { Paketleme, operatör seçimi, geri dönüşüm, güncelleme sıklığı, yeniden üretim, } \\
\text { bertaraf, ayırma, sipariş yönetimi, yeniden kullanım, geri çağırma, servis, azaltma }\end{array}$ \\
\hline & & Fiyatlama & Maliyet, bilgi teknolojileri navlun ödemesi, maliyet tasarrufu, karlılık \\
\hline \multirow[t]{4}{*}{ Jain ve Khan (2017) } & \multirow[t]{4}{*}{ AHP } & Toplama ve ayırma & $\begin{array}{l}\text { Ürün serisini toplama yeteneği, ürün serisini yönetme yeteneği, ürün serisini depolama } \\
\text { yeteneği, iş etiği }\end{array}$ \\
\hline & & Demontaj & Ürün serisini demonte etme yeteneği, ekonomiklik, benzer ürünler deneyimi \\
\hline & & Yönetim uygulamaları & Yeşil politikalar, taahhüt \\
\hline & & Hizmet düzeyi & Zamanında teslimat, kalite, ağ kapsamı \\
\hline \multirow{4}{*}{$\begin{array}{l}\text { Kiani Mavi vd. } \\
(2017)\end{array}$} & \multirow{4}{*}{$\begin{array}{l}\text { Bulanık SWARA- } \\
\text { Bulanık MOORA }\end{array}$} & Ekonomik & Kalite, maliyet, teslim süresi, teslimat deneyimi, nakliyat, hizmetler, teknik yenilik \\
\hline & & Çevre & $\begin{array}{l}\text { Geri dönüşüm, bertaraf, yeniden üretim, yeniden kullanım, Eko-tasarım üretim, yeşil } \\
\text { tasarım }\end{array}$ \\
\hline & & Sosyal & Sağlık ve güvenlik, müşterinin sesi, yerel kurallara ve politikalara sayg1 \\
\hline & & Risk & $\begin{array}{l}\text { İşgücü eşitliği ve tedarikçi stok yönetimi, esnek çalışma düzenlemeleri, istikrarlı } \\
\text { istihdam, operasyonel risk, örgütsel risk, finansal risk }\end{array}$ \\
\hline $\begin{array}{l}\text { Çalık ve Paksoy } \\
(2017)\end{array}$ & $\begin{array}{l}\text { Aralık Tip-2 Bulanık } \\
\text { AHP }\end{array}$ & \multicolumn{2}{|c|}{$\begin{array}{l}\text { Kalite, teslim edilebilirlik, tersine lojistik maliyeti, iade oranı, teknik/mühendislik yeteneği, talep karşılama yetersizliği, } \\
\text { isteklilik ve tutum }\end{array}$} \\
\hline \multirow{4}{*}{$\begin{array}{l}\text { Zarbakhshnia vd. } \\
\text { (2018) }\end{array}$} & \multirow{4}{*}{$\begin{array}{l}\text { Bulanık SWARA- } \\
\text { Bulanık COPRAS }\end{array}$} & Ekonomik & Kalite, maliyet, teslim süresi, teslimat ve hizmetler, nakliye \\
\hline & & Çevre & $\begin{array}{l}\text { Geri dönüşüm, bertaraf, yeniden üretim/yeniden kullanım, yeşil teknoloji yeteneği, } \\
\text { çevre koruma sertifikaları, Eko-tasarım üretim }\end{array}$ \\
\hline & & Sosyal & Sağlık ve güvenlik, müşterinin sesi, istikrarlı istihdam \\
\hline & & Risk & Operasyonel risk, finansal risk \\
\hline Ayçin (2018) & Gri DEMATEL & \multicolumn{2}{|c|}{$\begin{array}{l}\text { Teknolojik yeterlilik, esneklik, hizmet kalitesi, zamanında dağıtım performansı, müşteri ilişkileri, maliyetler, finansal } \\
\text { istikrar, firma imajı, firma konumu }\end{array}$} \\
\hline
\end{tabular}


Arsu, T., Ayçin, E. / Journal of Yasar University, 2021, 16/63, 1282-1300

\begin{tabular}{|c|c|c|c|}
\hline \multirow[t]{3}{*}{ Govindan vd. (2019) } & \multirow[t]{3}{*}{$\begin{array}{l}\text { Bulanık AHP- } \\
\text { TOPSIS }\end{array}$} & Ekonomik & $\begin{array}{l}\text { Hizmetlerin maliyeti, itibar ve pazardaki konum, teslimat güvenilirliği, teknolojik } \\
\text { uzmanlık, coğrafi konum }\end{array}$ \\
\hline & & Çevre & $\begin{array}{l}\text { Kaynak tüketimi, çevre koruma politikaları, uluslararası standartlar örgütü ile } \\
\text { uyumluluk (ISO14001), Yeşil dağıtım stratejileri ve etkin nakliye ağı, Emisyon/atık } \\
\text { sular ve atık üretimi }\end{array}$ \\
\hline & & Sosyal & $\begin{array}{l}\text { Sağlık ve güvenlik uygulamaları, personel eğitimi, yerel toplulukların etkisi, } \\
\text { Uluslararası Çalışma Örgütü koduna uyum, işgücünde eşitlik }\end{array}$ \\
\hline \multirow{4}{*}{$\begin{array}{l}\text { Zarbakhshnia vd. } \\
(2020)\end{array}$} & \multirow{4}{*}{$\begin{array}{l}\text { Bulanık AHP- Gri } \\
\text { MOORA }\end{array}$} & Ekonomik & Kalite, maliyet, teslim süresi, teslimat, hizmetler, Ar\&Ge Yeteneği \\
\hline & & Çevre & $\begin{array}{l}\text { Yeşil tasarım, yeniden kullanım, yeniden üretim, yenileme, geri dönüşüm, bertaraf, } \\
\text { hava emisyonları, yeşil paketleme }\end{array}$ \\
\hline & & Sosyal & Sağlık, esnek çalışma düzenlemeleri, müşterinin sesi, politikalara sayg1, itibar \\
\hline & & Risk ve Güvenlik & Operasyonel risk, örgütsel risk, finansal risk, güvenlik \\
\hline
\end{tabular}


3PTLS'lerin seçiminde ÇKKV yöntemleri dışında da birçok yöntem kullanılmaktadır. Min ve Ko (2008) 3PTLS'lerin seçiminde genetik algoritmalar, Xiangru (2008) bulanık kapsamlı değerlendirme, Govindan vd. (2012) yorumlayıcı yapısal modelleme ve Suyabatmaz vd. (2014) hibrid bir simülasyon yöntemi kullanmıştır.

Kiani Mavi vd. (2017) ve Zarbakhshnia vd. (2018) yaptıkları çalışmalarında kriterleri değerlendirme aşamasında bulanık SWARA yöntemi kullanmışlardır. Fakat bu çalışmaların temel amacı kriterleri değerlendirmekten ziyade 3PTLS alternatiflerini değerlendirmektir. Kriter yapısı olarak ise ekonomik, çevresel, sosyal ve risk ana kriterler ve bunlara ait alt kriterleri dikkate almışlardır. Mevcut çalışmada daha kapsamlı bir kriter yapısı oluşturulması hedeflenerek, tersine lojistik faaliyetleri, tersine lojistik fonksiyonları, kalite ve çevresel kriterler detaylandırılmış ayrıca bu çalışmalarda dikkate alınmayan teknoloji/iletişim yetenekleri ve deneyim gibi ana kriterler ve bunlara ait alt kriterler çalışma kapsamında incelenmiştir. Böylelikle bahsi geçen çalışmalardan daha kapsamlı bir kriter yapısı oluşturularak, literatürün geliştirilmesi hedeflenmiştir.

Ayrıca yapılan literatür incelemesi sonucunda diğer ÇKKV yöntemlerinin genellikle 3PTLS alternatifleri arasından seçim yapma üzerine odaklandığı görülmüştür. Kriter seçiminin karar alternatiflerinin değerlendirmesini doğrudan etkilediği düşünüldügünden, bu konuda karar vericilere bir rehber sağlamak 3PTLS alternatif seçiminde kritik bir öneme sahiptir. Bu noktadan hareketle 8 kriter altında yer alan 33 alt kriter ile yapılan kriter değerlendirmesinin, karar vericiler ve bu konuda çalışan bilim insanları açısından yol gösterebileceği düşüncesi bu çalışmanın temel çıkış noktasını oluşturmuştur.

\section{Materyal ve Yöntem}

SWARA (The step-wise weight assessment ratio analysis) yöntemi Keršuliene vd. tarafından geliştirilen, kriterlerin önem ağırlıklarının hesaplanmasında kullanılan bir yöntemdir. Kriterlerin değerlendirilmesinde uzman görüşünden yararlanılmaktadır. Dolayısıyla kriterlerin önem ağırlıklarını hesaplanırken yararlanılan uzman görüşlerinin tahmin yeteneği, SWARA yönteminin ana unsurlarından biridir (Keršuliene vd., 2010).

Karar problemlerinde yer alan belirsizlik unsurları, bu problemlerin çözümünde geleneksel yöntemlerin etkinliğini azaltabilmektedir. Dolayısıyla literatürde bulanık mantık ile çok kriterli karar verme yöntemlerinin bir arada kullanıldığı çalışmaların sayılarının arttığı görülmektedir. Bulanık mantık yaklaşımı ile SWARA yönteminin bir arada kullanıldığı Bulanık SWARA yöntemi 6 adımdan oluşan bir uygulama sürecine sahiptir (Kiani Mavi vd., 2017; Zarbakhshnia vd., 2018; Perçin, 2019) 
Adım 1. Kriterler önem düzeylerine göre sıralanır.

Adım 2. Kriterlerin göreceli önem düzeyleri belirlenir $\left(\tilde{s}_{j}\right)$ : Bu adımda $j$. kriterin $(j-1)$. kritere göre ne kadar önemli olduğu uzmanlar tarafından belirlenir. Değerlendirmeler yapılırken kullanılacak dilsel değişkenler ve bulanık sayı karşılıkları Tablo 2'de gösterilmiştir.

Tablo 2. Bulanık Değerlendirme Skalası

\begin{tabular}{cc}
\hline Dilsel değişkenler & Bulanık sayılar \\
\hline Çok düşük (ÇD) & $(0,0,0.30)$ \\
\hline Düşük $(\mathrm{D})$ & $(0,0.25,0.50)$ \\
\hline Orta $(\mathrm{O})$ & $(0.30,0.50,0.70)$ \\
\hline Yüksek $(\mathrm{Y})$ & $(0.50,0.75,1)$ \\
\hline Çok yüksek (ÇY) & $(0.70,1,1)$ \\
\hline Kaynak: Perçin, 2019, s. 534
\end{tabular}

Adım 3. $\left(\tilde{k}_{j}\right)$ değerleri Eşitlik (1)'den yararlanılarak hesaplanır.

$$
\tilde{k}_{j}=\left\{\begin{array}{cc}
\tilde{1} & j=1 \\
\tilde{s}_{j}+\tilde{1} & j>1
\end{array}\right.
$$

Adım 4. Bulanık ağırlıklar $\left(\tilde{q}_{j}\right)$ Eşitlik (2)'den yararlanılarak hesaplanır.

$$
\tilde{q}_{j}= \begin{cases}\tilde{1} & j=1 \\ \frac{\tilde{x}_{j-1}}{\tilde{k}_{j}} & j>1\end{cases}
$$

Adım 5. Kriterlerin göreceli bulanık ağırlıkları $\left(\widetilde{w}_{j}\right)$ Eşitlik (3)’ten yararlanılarak hesaplanır.

$$
\widetilde{w}_{j}=\frac{\tilde{q}_{j}}{\sum_{k=1}^{n} \tilde{q}_{k}}
$$

Adım 6. Yöntemin son aşamasında bir önceki aşamada elde edilen bulanık ağırlıklar Eşitlik (4)'ten yararlanılarak durulaştırılır. Burada $\tilde{A}$ üçgen bir bulanık sayı olmak üzere; 1 alt değeri, $\mathrm{m}$ orta değeri ve $\mathrm{u}$ ise üst değeri temsil eder.

$$
d(\tilde{A})=\frac{1}{3}(l+m+u)
$$

Bulanık SWARA yönteminin hesaplamalarında kullanılacak olan, $A_{1}\left(l_{1}, m_{1}, u_{1}\right)$ ve $A_{2}$ $\left(l_{2}, m_{2}, u_{2}\right)$ üçgen bulanık sayıları için temel matematiksel işlemler ise Eşitlik (5)-(8)'de gösterilmiştir.

$$
\begin{gathered}
A_{1}+A_{2}=\left(l_{1}+l_{2}, m_{1}+m_{2},+u_{1}+u_{2}\right) \\
A_{1}-A_{2}=\left(l_{1}-u_{2}, m_{1}-m_{2}, u_{1}-l_{2}\right) \\
A_{1} \times A_{2}=\left(l_{1} \cdot l_{2}, m_{1} \cdot m_{2}, u_{1} \cdot u_{2}\right) \\
A_{1} \div A_{2}=\left(l_{1} / u_{2}, m_{1} / m_{2}, u_{1} / l_{2}\right)
\end{gathered}
$$




\section{Uygulama}

Çalışmanın bu bölümünde 3PTLS seçiminde dikkate alınan kriterlerin bulanık SWARA yöntemiyle değerlendirildiği örnek bir uygulamaya yer verilmiştir. Bu doğrultuda öncelikle detaylı bir şekilde literatür taraması gerçekleştirilmiş ve 8 ana kriter ve 33 alt kriterden oluşmak üzere seçim kriterleri belirlenmiştir. Çalışma kapsamında yer alan 3PTLS seçim kriterleri Tablo 3’te özetlenmiştir. 
Tablo 3. Uygulama Kapsamındaki 3PTLS Seçim Kriterleri

\begin{tabular}{|c|c|c|}
\hline ANA KRITERLER & ALT KRITTERLER & REFERANSLAR \\
\hline \multirow{7}{*}{$\begin{array}{l}\text { TEMEL } \\
\text { YETENEKLER } \\
\quad(\text { K1) }\end{array}$} & Zamanında Teslim (K11) & $\begin{array}{l}\text { Meade ve Sarkis (2002); Efendigil vd. (2008); Govindan vd. (2013); Senthil vd. (2014); Prakash ve Barua } \\
\text { (2016a); Prakash ve Barua (2016b); Tavana vd. (2016); Jain ve Khan (2017); Kiani Mavi vd. (2017); } \\
\text { Zarbakhshnia vd. (2018); Ayçin (2018); Zarbakhshnia vd. (2020) }\end{array}$ \\
\hline & Nakliye Kapasitesi (K12) & Senthil vd. (2014); Prakash ve Barua (2016b); Kiani Mavi vd. (2017) \\
\hline & Esneklik (K13) & $\begin{array}{l}\text { Meade ve Sarkis (2002); Efendigil vd. (2008); Govindan vd. (2013); Senthil vd. (2014); Prakash ve Barua } \\
\text { (2016a); Prakash ve Barua (2016b); Tavana vd. (2016); Ayçin (2018) }\end{array}$ \\
\hline & Ulaştırma Ağ1 Kapsamı (K14) & Zhang ve Feng (2007); Govindan vd. (2013); Senthil vd. (2014); Jain ve Khan (2017); \\
\hline & Depo Yönetimi (K15) & Cheng ve Lee (2010); Govindan vd. (2013); Tavana vd. (2016); \\
\hline & Sipariş Yönetimi (K16) & Cheng ve Lee (2010); Govindan vd. (2013); Tavana vd. (2016); \\
\hline & Gelişmiş Ekipman Düzeyi (K17) & Zhang ve Feng (2007); Prakash ve Barua (2016a); Prakash ve Barua (2016b); \\
\hline \multirow{6}{*}{$\begin{array}{l}\text { TERSINE LOJISTIK } \\
\text { FAALIYETLERI } \\
\quad \text { (K2) }\end{array}$} & Geri Çağırma (K21) & Meade ve Sarkis (2002); Govindan vd. (2013); Senthil vd. (2014); Tavana vd. (2016) \\
\hline & Geri Dönüşüm (K22) & $\begin{array}{l}\text { Meade ve Sarkis (2002); Govindan vd. (2013); Senthil vd. (2014); Prakash ve Barua (2016b); Tavana vd. } \\
\text { (2016); Kiani Mavi vd. (2017); Zarbakhshnia vd. (2018); Zarbakhshnia vd. (2020) }\end{array}$ \\
\hline & Yeniden Üretim (K23) & $\begin{array}{l}\text { Meade ve Sarkis (2002); Cheng ve Lee (2010); Govindan vd. (2013); Senthil vd. (2014); Prakash ve } \\
\text { Barua (2016b); Tavana vd. (2016); Kiani Mavi vd. (2017); Zarbakhshnia vd. (2018); Zarbakhshnia vd. } \\
\text { (2020) }\end{array}$ \\
\hline & Yeniden Kullanım (K24) & $\begin{array}{l}\text { Meade ve Sarkis (2002); Cheng ve Lee (2010); Govindan vd. (2013); Senthil vd. (2014); Tavana vd. } \\
\text { (2016); Kiani Mavi vd. (2017); Zarbakhshnia vd. (2018); Zarbakhshnia vd. (2020) }\end{array}$ \\
\hline & Yenileme (K25) & Cheng ve Lee (2010); Prakash ve Barua (2016b); Zarbakhshnia vd. (2020) \\
\hline & Bertaraf (K26) & $\begin{array}{l}\text { Meade ve Sarkis (2002); Cheng ve Lee (2010); Govindan vd. (2013); Senthil vd. (2014); Prakash ve } \\
\text { Barua (2016b); Tavana vd. (2016); Kiani Mavi vd. (2017); Zarbakhshnia vd. (2018); Zarbakhshnia vd. } \\
\text { (2020) }\end{array}$ \\
\hline \multirow{5}{*}{$\begin{array}{l}\text { TERSINE LOJISTIK } \\
\text { FONKSIYYONLARI } \\
\quad(\text { K3) }\end{array}$} & Toplama (K31) & $\begin{array}{l}\text { Meade ve Sarkis (2002); Senthil vd. (2014); Prakash ve Barua (2016a); Prakash ve Barua (2016b); Tavana } \\
\text { vd. (2016) }\end{array}$ \\
\hline & Ayırma (K32) & Meade ve Sarkis (2002); Senthil vd. (2014); Prakash ve Barua (2016a); Prakash ve Barua (2016b) \\
\hline & Paketleme (K33) & Meade ve Sarkis (2002); Senthil vd. (2014); Govindan vd. (2013); Tavana vd. (2016) \\
\hline & Teslimat (K34) & Meade ve Sarkis (2002); Senthil vd. (2014): Tavana vd. (2016) \\
\hline & Depolama (K35) & $\begin{array}{l}\text { Meade ve Sarkis (2002); Senthil vd. (2014); Prakash ve Barua (2016a): Prakash ve Barua (2016b); Tavana } \\
\text { vd. (2016) }\end{array}$ \\
\hline \multirow{3}{*}{$\begin{array}{l}\text { TEKNOLOJİ VE } \\
\text { İLETIŞ̧iM } \\
\text { YETERLİİKLERİ } \\
\text { (K4) }\end{array}$} & $\begin{array}{l}\text { Takip ve İzleme Teknolojileri } \\
\text { (K41) }\end{array}$ & Zhang ve Feng (2007); Cheng ve Lee (2010); Govindan vd. (2013); Prakash ve Barua (2016b); \\
\hline & Bilgi Tek. Altyapısı (K42) & $\begin{array}{l}\text { Cheng ve Lee (2010); Govindan vd. (2013); Senthil vd. (2014); Prakash ve Barua (2016a); Tavana vd. } \\
\text { (2016) }\end{array}$ \\
\hline & Etkili İletişim (K43) & Govindan vd. (2013); Tavana vd. (2016); Prakash ve Barua (2016a): Prakash ve Barua (2016b) \\
\hline
\end{tabular}




\begin{tabular}{|c|c|c|}
\hline \multirow{3}{*}{$\begin{array}{l}\text { ÇEVRESEL } \\
\text { ETMENLER } \\
\quad(\text { K5) }\end{array}$} & Çevre Bilinci (K51) & $\begin{array}{l}\text { Efendigil vd. (2008); Hsueh ve Lin (2015); Kiani Mavi vd. (2017); Zarbakhshnia vd. (2018); Govindan } \\
\text { vd. (2019); Zarbakhshnia vd. (2020) }\end{array}$ \\
\hline & $\begin{array}{l}\text { Yeşil Uygulamaların Kullanımı } \\
\text { (K52) }\end{array}$ & $\begin{array}{l}\text { Jain ve Khan (2017); Kiani Mavi vd. (2017); Zarbakhshnia vd. (2018); Govindan vd. (2019); } \\
\text { Zarbakhshnia vd. (2020) }\end{array}$ \\
\hline & Çevre Koruma Sertifikaları (K53) & Zarbakhshnia vd. (2018); Govindan vd. (2019) \\
\hline \multirow{3}{*}{$\begin{array}{l}\text { KALİTE } \\
\quad \text { (K6) }\end{array}$} & Hizmet Kalitesi (K61) & $\begin{array}{l}\text { Meade ve Sarkis (2002); Zhang ve Feng (2007); Efendigil vd. (2008); Kannan vd. (2009); Saen (2010); } \\
\text { Senthil vd. (2014); Prakash ve Barua (2016b); Tavana vd. (2016); Jain ve Khan (2017); Kiani Mavi vd. } \\
\text { (2017); Çalık ve Paksoy (2017); Ayçin (2018); Zarbakhshnia vd. (2018); Zarbakhshnia vd. (2020) }\end{array}$ \\
\hline & Müşteri Memnuniyeti (K62) & $\begin{array}{l}\text { Zhang ve Feng (2007); Efendigil vd. (2008); Tavana vd. (2016); Kiani Mavi vd. (2017); Zarbakhshnia vd. } \\
\text { (2018); Zarbakhshnia vd. (2020) }\end{array}$ \\
\hline & Kişiye Özel Hizmetler (K63) & Zhang ve Feng (2007); Senthil vd. (2014); Prakash ve Barua (2016a); Prakash ve Barua (2016b) \\
\hline \multirow{3}{*}{$\begin{array}{l}\text { MALIYETLER } \\
\text { (K7) }\end{array}$} & Toplam Maliyet (K71) & Saen (2009); Saen (2010); Sasikumar ve Haq (2011); Hsueh ve Lin (2015); \\
\hline & Tersine Lojistik Maliyeti (K72) & Kannan vd. (2009); Sasikumar ve Haq (2011); Prakash ve Barua (2016b); Çalık ve Paksoy (2017) \\
\hline & Fursat Maliyeti (K73) & Hsueh ve Lin (2015) \\
\hline \multirow{3}{*}{$\begin{array}{l}\text { DENEYİM } \\
\text { (K8) }\end{array}$} & Sektör Deneyimi (K81) & Senthil vd. (2014); Prakash ve Barua (2016a); Kiani Mavi vd. (2017); Govindan vd. (2019) \\
\hline & Kurumsal İmaj/ İtibar (K82) & Prakash ve Barua (2016a); Ayçin (2018); Govindan vd. (2019); Zarbakhshnia vd. (2020) \\
\hline & Geçmiş Performans (K83) & Zhang ve Feng (2007); Senthil vd. (2014) \\
\hline
\end{tabular}


Kriterler belirlendikten sonra Bulanık SWARA yöntemi ile çözüm değerlerinin elde edilebilmesi için konu ile ilgili iki akademisyen ve üç mühendisten oluşan uzman beş kişilik bir grubun görüşü alınmıştır. Karar verme sürecinde yer alan iki akademisyen, lojistik faaliyetleri ile ilgili akademik çalışmaları bulunan ve yirmi yıla yakın mesleki deneyimi olan kişilerden seçilmiştir. On yılın üzerinde sektörel deneyimi bulunan üç mühendis ise, lojistik alanında faaliyet gösteren bir firmada endüstri mühendisi olarak görev yapmaktadır. Beş kişilik uzman grubun bir araya gelerek yaptıkları görüşmeler ve değerlendirmeler sonucunda konsensusa vardıktan sonra grup karar verme süreci tamamlanmıştır. Grup kararı sonucunda elde edilen değerlendirmeler doğrultusunda yöntemin uygulama adımları uygulanmış ve sonuçların elde edilmesi amaçlanmıştır. Uygulama adımlarını gösteren bir akış şeması Şekil 1 'de gösterilmiştir.

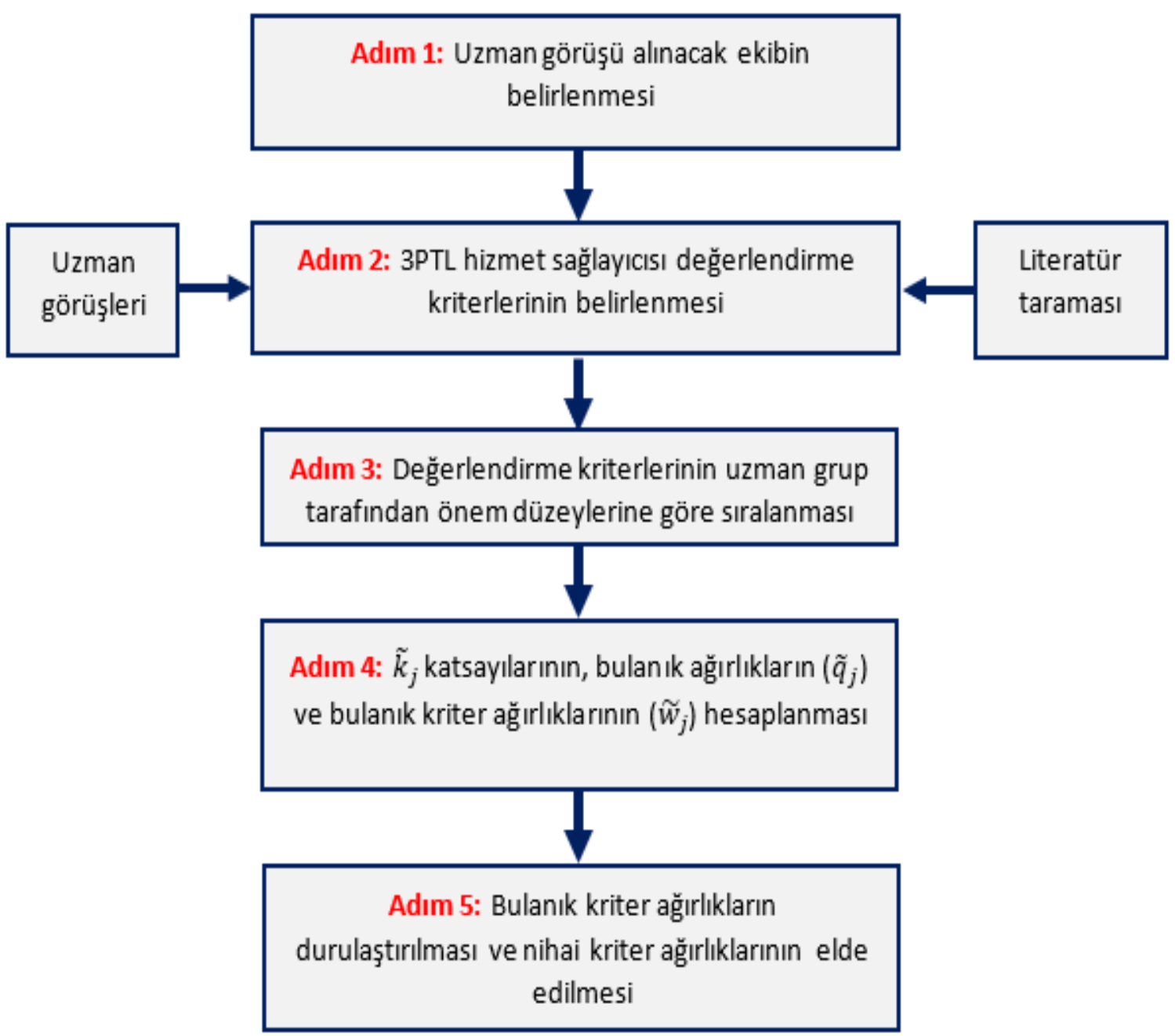

Şekil 1. Bulanık SWARA Yöntemi ile 3PTLS Seçim Süreci 


\section{Bulgular}

Tablo 2'de yer alan dilsel değişkenler ve Eşitlik (1)-(3)'den yararlanılarak hem ana kriterler için hem de alt kriterler için yapılan hesaplamalar Tablo 4 ve Tablo 5'te gösterilmiştir. Hesaplamalar yapılırken, bulanık sayılarla yapılan işlemler için Eşitlik (5)-(8)'den yararlanılmıştır.

Tablo 4. Ana Kriterler İçin Hesaplamalar

\begin{tabular}{lcccccccccccc}
\hline Ana Kriterler & & $\tilde{s}_{j}$ & \multicolumn{4}{c}{$\tilde{k}_{j}=\left(\tilde{s}_{j}+1\right)$} & \multicolumn{4}{c}{$\tilde{q}_{j}$} \\
\hline K1 & & & & 1 & 1 & 1 & 1 & 1 & 1 & 0,152 & 0,175 & 0,298 \\
K6 & 0 & 0 & 0,3 & 1,00 & 1,00 & 1,30 & 0,769 & 1,000 & 1,000 & 0,117 & 0,175 & 0,298 \\
K5 & 0 & 0 & 0,3 & 1,00 & 1,00 & 1,30 & 0,592 & 1,000 & 1,000 & 0,090 & 0,175 & 0,298 \\
K8 & 0,30 & 0,5 & 0,70 & 1,30 & 1,50 & 1,70 & 0,348 & 0,667 & 0,769 & 0,053 & 0,117 & 0,229 \\
K7 & 0 & 0 & 0,3 & 1,00 & 1,00 & 1,30 & 0,268 & 0,667 & 0,769 & 0,041 & 0,117 & 0,229 \\
K2 & 0 & 0,25 & 0,5 & 1,00 & 1,25 & 1,50 & 0,178 & 0,533 & 0,769 & 0,027 & 0,093 & 0,229 \\
K3 & 0 & 0 & 0,3 & 1,00 & 1,00 & 1,30 & 0,137 & 0,533 & 0,769 & 0,021 & 0,093 & 0,229 \\
K4 & 0,50 & 0,75 & 1,00 & 1,50 & 1,75 & 2,00 & 0,069 & 0,305 & 0,513 & 0,010 & 0,053 & 0,153 \\
\hline
\end{tabular}

Tablo 5. Alt Kriterler İçin Hesaplamalar

Temel Yetenekler (K1) Alt Kriterleri

\begin{tabular}{lcccccccccccc}
\hline \multicolumn{1}{c}{} & \multicolumn{1}{c}{$\tilde{s}_{j}$} & \multicolumn{1}{c}{$\tilde{k}_{j}=\left(\tilde{s}_{j}+1\right)$} & \multicolumn{1}{c}{$\tilde{q}_{j}$} & & & $\widetilde{w}_{j}$ \\
\hline $\mathrm{K} 11$ & & & & 1 & 1 & 1 & 1 & 1 & 1 & 0,240 & 0,319 & 0,416 \\
$\mathrm{~K} 14$ & 0,30 & 0,5 & 0,70 & 1,3 & 1,5 & 1,7 & 0,588 & 0,667 & 0,769 & 0,141 & 0,213 & 0,320 \\
$\mathrm{~K} 13$ & 0,50 & 0,75 & 1,00 & 1,5 & 1,75 & 2 & 0,294 & 0,381 & 0,513 & 0,071 & 0,121 & 0,213 \\
$\mathrm{~K} 12$ & 0 & 0,25 & 0,5 & 1 & 1,25 & 1,5 & 0,196 & 0,305 & 0,513 & 0,047 & 0,097 & 0,213 \\
$\mathrm{~K} 17$ & 0 & 0 & 0,3 & 1 & 1 & 1,3 & 0,151 & 0,305 & 0,513 & 0,036 & 0,097 & 0,213 \\
$\mathrm{~K} 15$ & 0 & 0 & 0,3 & 1 & 1 & 1,3 & 0,116 & 0,305 & 0,513 & 0,028 & 0,097 & 0,213 \\
$\mathrm{~K} 16$ & 0,50 & 0,75 & 1,00 & 1,5 & 1,75 & 2 & 0,058 & 0,174 & 0,342 & 0,014 & 0,056 & 0,142 \\
\hline
\end{tabular}

Tersine Lojistik Faaliyetleri (K2) Alt Kriterleri

\begin{tabular}{|c|c|c|c|c|c|c|c|c|c|c|c|c|}
\hline & \multicolumn{3}{|c|}{$\tilde{S}_{j}$} & \multicolumn{3}{|c|}{$\tilde{k}_{j}=\left(\tilde{s}_{j}+1\right)$} & \multicolumn{3}{|c|}{$\tilde{q}_{j}$} & \multicolumn{3}{|c|}{$\widetilde{w}_{j}$} \\
\hline K22 & & & & 1 & 1 & 1 & 1 & 1 & 1 & 0,231 & 0,249 & 0,347 \\
\hline $\mathrm{K} 23$ & 0 & 0 & 0,3 & 1 & 1 & 1,3 & 0,769 & 1,000 & 1,000 & 0,178 & 0,249 & 0,347 \\
\hline K25 & 0 & 0 & 0,3 & 1 & 1 & 1,3 & 0,592 & 1,000 & 1,000 & 0,137 & 0,249 & 0,347 \\
\hline K24 & 0,50 & 0,75 & 1,00 & 1,5 & 1,75 & 2 & 0,296 & 0,571 & 0,667 & 0,068 & 0,142 & 0,232 \\
\hline K21 & 0,70 & 1 & 1,00 & 1,7 & 2 & 2 & 0,148 & 0,286 & 0,392 & 0,034 & 0,071 & 0,136 \\
\hline K26 & 0,50 & 0,75 & 1,00 & 1,5 & 1,75 & 2 & 0,074 & 0,163 & 0,261 & 0,017 & 0,041 & 0,091 \\
\hline \multicolumn{13}{|c|}{ Tersine Lojistik Fonksiyonları (K3) Alt Kriterleri } \\
\hline & \multicolumn{3}{|c|}{$\tilde{s}_{j}$} & \multicolumn{3}{|c|}{$\tilde{k}_{j}=\left(\tilde{s}_{j}+1\right)$} & \multicolumn{3}{|c|}{$\tilde{q}_{j}$} & \multicolumn{3}{|c|}{$\widetilde{w}_{j}$} \\
\hline K31 & & & & 1 & 1 & 1 & 1 & 1 & 1 & 0,214 & 0,235 & 0,339 \\
\hline K32 & 0 & 0 & 0,3 & 1 & 1 & 1,3 & 0,769 & 1,000 & 1,000 & 0,165 & 0,235 & 0,339 \\
\hline K34 & 0 & 0 & 0,3 & 1 & 1 & 1,3 & 0,592 & 1,000 & 1,000 & 0,127 & 0,235 & 0,339 \\
\hline K35 & 0 & 0,25 & 0,5 & 1 & 1,25 & 1,5 & 0,394 & 0,800 & 1,000 & 0,085 & 0,188 & 0,339 \\
\hline K33 & 0,50 & 0,75 & 1,00 & 1,5 & 1,75 & 2 & 0,197 & 0,457 & 0,667 & 0,042 & 0,107 & 0,226 \\
\hline
\end{tabular}

Teknoloji ve İletişim Yeterlilikleri (K4) Alt Kriterleri

\begin{tabular}{|c|c|c|c|c|c|c|c|c|c|c|c|c|}
\hline & \multicolumn{3}{|c|}{$\tilde{s}_{j}$} & \multicolumn{3}{|c|}{$\tilde{k}_{j}=\left(\tilde{s}_{j}+1\right)$} & \multicolumn{3}{|c|}{$\tilde{q}_{j}$} & \multicolumn{3}{|c|}{$\widetilde{w}_{j}$} \\
\hline K43 & & & & 1 & 1 & 1 & 1 & 1 & 1 & 0,333 & 0,357 & 0,438 \\
\hline K42 & 0 & 0 & 0,3 & 1 & 1 & 1,3 & 0,769 & 1,000 & 1,000 & 0,256 & 0,357 & 0,438 \\
\hline K41 & 0 & 0,25 & 0,5 & 1 & 1,25 & 1,5 & 0,513 & 0,800 & 1,000 & 0,171 & 0,286 & 0,438 \\
\hline \multicolumn{13}{|c|}{ Çevresel Etmenler (K5) Alt Kriterleri } \\
\hline & \multicolumn{3}{|c|}{$\tilde{s}_{j}$} & \multicolumn{3}{|c|}{$\tilde{k}_{j}=\left(\tilde{s}_{j}+1\right)$} & \multicolumn{3}{|c|}{$\tilde{q}_{j}$} & \multicolumn{3}{|c|}{$\widetilde{w}_{j}$} \\
\hline K51 & & & & 1 & 1 & 1 & 1 & 1 & 1 & 0,375 & 0,389 & 0,464 \\
\hline K52 & 0 & 0 & 0,3 & 1 & 1 & 1,3 & 0,769 & 1,000 & 1,000 & 0,288 & 0,389 & 0,464 \\
\hline K53 & 0,50 & 0,75 & 1,00 & 1,5 & 1,75 & 2 & 0,385 & 0,571 & 0,667 & 0,144 & 0,222 & 0,310 \\
\hline
\end{tabular}

Kalite (K6) Alt Kriterleri 


\begin{tabular}{|c|c|c|c|c|c|c|c|c|c|c|c|c|}
\hline K62 & & & & 1 & 1 & 1 & 1 & 1 & 1 & 0,361 & 0,375 & 0,450 \\
\hline K61 & 0 & 0 & 0,3 & 1 & 1 & 1,3 & 0,769 & 1,000 & 1,000 & 0,278 & 0,375 & 0,450 \\
\hline K63 & 0,30 & 0,5 & 0,70 & 1,3 & 1,5 & 1,7 & 0,452 & 0,667 & 0,769 & 0,163 & 0,250 & 0,346 \\
\hline \multicolumn{13}{|c|}{ Maliyetler (K7) Alt Kriterleri } \\
\hline & \multicolumn{3}{|c|}{$\tilde{s}_{j}$} & \multicolumn{3}{|c|}{$\tilde{k}_{j}=\left(\tilde{s}_{j}+1\right)$} & \multicolumn{3}{|c|}{$\tilde{q}_{j}$} & \multicolumn{3}{|c|}{$\widetilde{w}_{j}$} \\
\hline K71 & & & & 1 & 1 & 1 & 1 & 1 & 1 & 0,394 & 0,429 & 0,490 \\
\hline K72 & 0,30 & 0,5 & 0,70 & 1,3 & 1,5 & 1,7 & 0,588 & 0,667 & 0,769 & 0,232 & 0,286 & 0,377 \\
\hline K73 & 0 & 0 & 0,3 & 1 & 1 & 1,3 & 0,452 & 0,667 & 0,769 & 0,178 & 0,286 & 0,377 \\
\hline \multicolumn{13}{|c|}{ Deneyim (K8) Alt Kriterleri } \\
\hline & \multicolumn{3}{|c|}{$\tilde{s}_{j}$} & \multicolumn{3}{|c|}{$\tilde{k}_{j}=\left(\tilde{s}_{j}+1\right)$} & \multicolumn{3}{|c|}{$\tilde{q}_{j}$} & \multicolumn{3}{|c|}{$\widetilde{w}_{j}$} \\
\hline K82 & & & & 1 & 1 & 1 & 1 & 1 & 1 & 0,505 & 0,560 & 0,571 \\
\hline K81 & 0,70 & 1 & 1,00 & 1,70 & 2 & 2,00 & 0,500 & 0,500 & 0,588 & 0,252 & 0,280 & 0,336 \\
\hline K83 & 0,50 & 0,75 & 1,00 & 1,50 & 1,75 & 2,00 & 0,250 & 0,286 & 0,392 & 0,126 & 0,160 & 0,224 \\
\hline
\end{tabular}

Uygulamanın son adımında, ana kriterler ve alt kriterler için Tablo 4 ve 5'te gösterildiği üzere hesaplanan bulanık ağırlıklar bütünleştirilmiştir. Nihai ağırlıkların elde edilebilmesi için Eşitlik (4)'ten yararlanılarak durulaştırma işlemi gerçekleştirilmiş ve son olarak ise bu ağırlıklar normalize edilmiștir. Yapılan işlemler sonucunda elde edilen nihai kriter ağırlıkları ve siralamalar Tablo 6' da gösterilmiştir.

Tablo 6. Nihai Kriter Ağırlıkları ve Sıralamalar

\begin{tabular}{|c|c|c|c|c|c|c|c|}
\hline \multirow{2}{*}{$\begin{array}{l}\text { Kriterler } \\
\text { K1 }\end{array}$} & \multicolumn{3}{|c|}{$\begin{array}{c}\text { Bütünleştirilmiş } \\
\text { Ağırlıklar }\end{array}$} & \multirow{2}{*}{$\begin{array}{c}\begin{array}{c}\text { Duru } \\
\text { Ağırliklar }\end{array} \\
0,208\end{array}$} & \multirow{2}{*}{$\begin{array}{c}\text { Normalize } \\
\text { Ağırlik }\end{array}$} & \multirow[t]{2}{*}{$\begin{array}{c}\text { Nihai } \\
\text { Ağırlıklar }\end{array}$} & \multirow[t]{2}{*}{ Siralama } \\
\hline & 0,152 & 0,175 & 0,298 & & & & \\
\hline K11 & 0,036 & 0,056 & 0,124 & 0,072 & 0,278 & 0,0500 & 6 \\
\hline K14 & 0,021 & 0,037 & 0,095 & 0,051 & 0,198 & 0,0356 & 10 \\
\hline K13 & 0,011 & 0,021 & 0,063 & 0,032 & 0,123 & 0,0221 & 17 \\
\hline K12 & 0,007 & 0,017 & 0,063 & 0,029 & 0,113 & 0,0203 & 25 \\
\hline K17 & 0,005 & 0,017 & 0,063 & 0,029 & 0,111 & 0,0199 & 27 \\
\hline K15 & 0,004 & 0,017 & 0,063 & 0,028 & 0,109 & 0,0196 & 28 \\
\hline K16 & 0,002 & 0,010 & 0,042 & 0,018 & 0,070 & 0,0125 & 31 \\
\hline $\mathrm{K} 2$ & 0,027 & 0,093 & 0,229 & 0,116 & 0,101 & & \\
\hline K22 & 0,006 & 0,023 & 0,079 & 0,036 & 0,240 & 0,0241 & 14 \\
\hline $\mathrm{K} 23$ & 0,005 & 0,023 & 0,079 & 0,036 & 0,236 & 0,0238 & 15 \\
\hline $\mathrm{K} 25$ & 0,004 & 0,023 & 0,079 & 0,035 & 0,234 & 0,0236 & 16 \\
\hline K24 & 0,002 & 0,013 & 0,053 & 0,023 & 0,150 & 0,0151 & 29 \\
\hline $\mathrm{K} 21$ & 0,001 & 0,007 & 0,031 & 0,013 & 0,085 & 0,0086 & 32 \\
\hline $\mathrm{K} 26$ & 0,000 & 0,004 & 0,021 & 0,008 & 0,055 & 0,0055 & 33 \\
\hline K3 & 0,021 & 0,093 & 0,229 & 0,114 & 0,099 & & \\
\hline K31 & 0,004 & 0,022 & 0,078 & 0,035 & 0,222 & 0,0219 & 18 \\
\hline K32 & 0,003 & 0,022 & 0,078 & 0,034 & 0,220 & 0,0217 & 19 \\
\hline K34 & 0,003 & 0,022 & 0,078 & 0,034 & 0,218 & 0,0216 & 20 \\
\hline K35 & 0,002 & 0,018 & 0,078 & 0,032 & 0,207 & 0,0204 & 24 \\
\hline K33 & 0,001 & 0,010 & 0,052 & 0,021 & 0,134 & 0,0132 & 30 \\
\hline K4 & 0,010 & 0,053 & 0,153 & 0,072 & 0,062 & & \\
\hline K43 & 0,003 & 0,019 & 0,067 & 0,030 & 0,341 & 0,0213 & 21 \\
\hline K42 & 0,003 & 0,019 & 0,067 & 0,030 & 0,338 & 0,0211 & 22 \\
\hline K41 & 0,002 & 0,015 & 0,067 & 0,028 & 0,320 & 0,0200 & 26 \\
\hline K5 & 0,090 & 0,175 & 0,298 & 0,188 & 0,162 & & \\
\hline K51 & 0,034 & 0,068 & 0,138 & 0,080 & 0,389 & 0,0631 & 2 \\
\hline K52 & 0,026 & 0,068 & 0,138 & 0,077 & 0,377 & 0,0611 & 4 \\
\hline K53 & 0,013 & 0,039 & 0,092 & 0,048 & 0,234 & 0,0379 & 9 \\
\hline K6 & 0,117 & 0,175 & 0,298 & 0,197 & 0,170 & & \\
\hline K62 & 0,042 & 0,066 & 0,134 & 0,081 & 0,378 & 0,0642 & 1 \\
\hline K61 & 0,032 & 0,066 & 0,134 & 0,077 & 0,363 & 0,0616 & 3 \\
\hline
\end{tabular}




\begin{tabular}{lllllllc} 
K63 & 0,019 & 0,044 & 0,103 & 0,055 & 0,259 & 0,0440 & 8 \\
\hline K7 & 0,041 & 0,117 & 0,229 & 0,129 & 0,111 & & \\
K71 & 0,016 & 0,050 & 0,112 & 0,059 & 0,410 & 0,0457 & 7 \\
K72 & 0,009 & 0,033 & 0,086 & 0,043 & 0,297 & 0,0331 & 12 \\
K73 & 0,007 & 0,033 & 0,086 & 0,042 & 0,292 & 0,0325 & 13 \\
\hline K8 & 0,053 & 0,117 & 0,229 & 0,133 & 0,115 & & \\
K82 & 0,027 & 0,065 & 0,131 & 0,074 & 0,528 & 0,0606 & 5 \\
K81 & 0,013 & 0,033 & 0,077 & 0,041 & 0,291 & 0,0334 & 11 \\
K83 & 0,007 & 0,019 & 0,051 & 0,026 & 0,181 & 0,0208 & 23 \\
\hline
\end{tabular}

Tablo 6'da gösterildiği üzere, 3PTLS seçimindeki en önemli kriterlerin sırasıyla K62: müşteri memnuniyeti $(0,0642), \mathrm{K} 51$ : çevre bilinci $(0,0631)$ ve K61: hizmet kalitesi $(0,0616)$ olduğu tespit edilmiştir. En önemsiz kriterlerin ise sırasıyla K26: bertaraf, K21: geri çağırma ve K16: sipariş yönetimi olduğu belirlenmiştir.

\section{Sonuç ve Değerlendirme}

Sınırsız insan ihtiyaçlarını karşılamada doğal kaynakların yetersiz kalması ve çevresel endişeler son yıllarda tersine lojistiğin önem kazanmasını sağlamıştır. Çünkü tersine lojistik hem kullanılmış ürünlerin yeniden kullanılması ile bakir hammadde ihtiyacını azaltmakta hem de kullanılmış ürünlerin doğaya bırakılmasını önleyerek çevreyi korumaktadır. Aynı zamanda tersine lojistik enerji kazanımı konusunda da faydalı bir süreçtir. Çünkü hem tersine lojistik sayesinde üretim için kullanılan enerji miktarı azalmakta hem de tersine lojistikten elde edilen girdiler yenilenebilir enerji üretiminde kullanılmaktadır. Bütün bu kazanımlar göz önünde bulundurulduğunda tersine lojistik işletmelere rekabet avantajı sağlamaktadır. Fakat tersine lojistiğin bu kazanımlarından yeterince faydalanmak için tersine lojistik servis sağlayıcısının seçimi hayati bir önem arz etmektedir. Bu noktadan hareketle bu çalışmada 3PTLS seçiminde kullanılan kriterlerin önem düzeyleri bulanık SWARA yöntemi ile belirlenmiştir.

Çalışma elde edilen bulgulara göre en önemli seçim kriterleri sırasıyla müşteri memnuniyeti, çevre bilinci ve hizmet kalitesi olarak bulunmuştur. Bulgular incelendiğinde en önemli seçim kriterleri kalite ve çevresel etmenler kriterlerinin alt kriterlerindendir. Herhangi bir hizmet için dış kaynak kullanan bir işletmenin en önemli kriterlerinin müşteri memnuniyeti ve hizmet kalitesi olması da şaşırtıcı bir sonuç değildir. Çünkü dış kaynağa ödediği bedelin tam olarak karşılığını istemektedir. Ayrıca son yıllarda işletmeler çevresel duyarlılığı halkla ilişkiler aracı olarak gördüklerinden 3PTLS'lerinden de çevre duyarlılığı istemeleri beklenen bir sonuçtur. En önemsiz seçim kriterleri ise bertaraf, geri çağırma ve sipariş yönetimidir. $\mathrm{Bu}$ sonuçlara göre bertaraf ve geri çağırmanın en önemsiz seçim kriterleri olmaları da beklenmedik bir sonuç değildir. Çünkü özellikle Türkiye'de geri çağırma sadece yüksek maliyetli bazı teknoloji ürünlerinde kullanılan bir tersine lojistik faaliyetidir ve işletmeler tarafindan maliyetli bir seçenek olduğundan pek tercih edilmemektedir. Yine aynı şekilde bertaraf da işletme için 
kar getirmeyen bir alan olduğundan işletmeler açısından diğer seçim kriterleri kadar önem arz etmemektedir.

Mevcut çalışmada elde edilen sonuçların literatürdeki benzer çalışmaların sonuçları ile kıyaslandığında, birtakım farklılıklar gösterdiği tespit edilmiştir. Kiani Mavi vd. (2017) ve Zarbakhshnia vd. (2018) çalışmalarında en önemli kriterleri sırasıyla kalite, maliyet ve geri dönüşüm olarak belirlerken; mevcut çalışmada ise sırasıyla müşteri memnuniyeti, çevre bilinci ve hizmet kalitesi kriterleri ön plana çıkmıştır.

Bu çalışmada 3PTLS seçim kriterlerinin bulanık SWARA yöntemi ile değerlendirildiği ve sonuçların başarılı bir şekilde ortaya koyulduğu bir uygulama gerçekleştirilmiştir. Çoğunlukla nitel kriterlerin yer aldığı 3PTLS seçim kriterlerinin dilsel ifadeler ile daha iyi değerlendirilebileceği düşünüldüğünden dolayı, subjektif bir kriter ağırlıklandırma yöntemi olan SWARA yönteminin bulanık mantık ile bir arada kurgulandığı bulanık SWARA yöntemi tercih edilmiştir. Ayrıca bulanık AHP, bulanık BWM vb. gibi diğer subjektif kriter ağırlıklandırma yöntemleri ile kıyaslandığında, bulanık SWARA yönteminin daha az ikili karşılaştırma ile çözüm yapma olanağı tanıması bu yöntemin en önemli avantajı olarak görülmektedir. 8 ana ve 33 alt kriter olmak üzere oldukça fazla sayıda kriterin bulunduğu mevcut çalışmada, daha az ikili karşılaştırma ile tutarlı değerlendirmeler yapılarak daha sağlıklı sonuçlar elde edilebilmesinin amaçlanması bulanık SWARA yönteminin tercih sebeplerinden biri olmuştur.

Gelecekte yapılacak çalışmalarda kullanılacak farklı ÇKKV yöntemleri ve kriter kombinasyonları farklı seçim kriterlerini önemli hale getirebilecektir. Ayrıca bu çalışmada beş kişilik bir uzman grubun konsorsiyumu sonucunda oluşan değerlendirmeler yardımıyla krtierlerin önem ağırlıkları hesaplanmıştır. Konu ile ilgili görüş bildirecek yetkinliğe sahip ulaşılabilen uzman sayısı bu çalışmanın kısıtlılıklarından birini oluşturmuştur. Farklı uzmanların görüşleri veya uzman görüşüne ihtiyaç duyulmayan ÇKKV yöntemlerinin kullanımı ile gelecek çalışmalarda farklı sonuçlar ortaya koyabilmek mümkün olacaktır. 


\section{KAYNAKÇA}

Ayçin, E. 2018. "Üçüncü parti lojistik hizmet sağlayıcı seçim kriterlerinin gri DEMATEL bütünleşik yaklaşımıyla belirlenmesi”. Alphanumeric Journal, 6(2), 277-292.

Çalık, A., \& Paksoy, T. 2017. "Aralık tip-2 bulanık AHP yöntemi ile üçüncü parti tersine lojistik (3PTL) firma seçimi”. Selçuk Üniversitesi Sosyal Bilimler Meslek Yüksekokulu Dergisi, 20(1), 52-67.

Chang, D.Y. 1996. “Applications of the extent analysis method on fuzzy AHP.” European Journal of Operational Research, 95(3), 649-655.

Cheng, Y.H., \& Lee, F. 2010. "Outsourcing reverse logistics of high-tech manufacturing firms by using a systematic decision-making approach: TFT-LCD sector in Taiwan." Industrial Marketing Management, 39(7), 1111-1119. https://doi.org/10.1016/j.indmarman.2009.10.004

Efendigil, T., Önüt, S., \& Kongar, E. 2008. "A holistic approach for selecting a third-party reverse logistics provider in the presence of vagueness." Computers \& Industrial Engineering, 54(2), 269-287. https://doi.org/10.1016/j.cie.2007.07.009

Ginter, P.M., \& Starling, J.M. 1978. "Reverse distribution channels for recycling." California Management Review, 20(3), 72-82. https://doi.org/10.2307/41165284

Govindan, K., Agarwal, V., Darbari, J.D., \& Jha, P. C. 2019. "An integrated decision making model for the selection of sustainable forward and reverse logistic providers." Annals of Operations Research, 273(12), 607-650. https://doi.org/10.1007/s10479-017-2654-5

Govindan, K., Palaniappan, M., Zhu, Q., \& Kannan, D. 2012. "Analysis of third party reverse logistics provider using interpretive structural modeling." International Journal of Production Economics, 140(1), 204-211. https://doi.org/10.1016/j.ijpe.2012.01.043

Govindan, K., Sarkis, J., \& Palaniappan, M. 2013. "An analytic network process-based multicriteria decision making model for a reverse supply chain." The International Journal of Advanced Manufacturing Technology, 68(1-4), 863-880. https://doi.org/10.1007/s00170-013-4949-2

Guiltinan, J.P., \& Nwokoye, N.G. 1975. "Developing distribution channels and systems in the emerging recycling industries." International Journal of Physical Distribution, 6(1), 28-38. https://doi.org/10.1108/eb014359

Hsueh, J.T., \& Lin, C.Y. 2015. "Constructing a network model to rank the optimal strategy for implementing the sorting process in reverse logistics: case study of photovoltaic industry." Clean Technologies and Environmental Policy, 17(1), 155-174. https://doi.org/10.1007/s10098-014-0770-3

Jain, V., \& Khan, S.A. 2017. "Application of AHP in reverse logistics service provider selection: a case study." International Journal of Business Innovation and Research, 12(1), 94-119. https://doi.org/10.1504/IJBIR.2017.080711

Kannan, G., Pokharel, S., \& Kumar, P.S. 2009. "A hybrid approach using ISM and fuzzy TOPSIS for the selection of reverse logistics provider." Resources, Conservation and Recycling, 54(1), 28-36. https://doi.org/10.1016/j.resconrec.2009.06.004

Keršuliene, V., Zavadskas, E.K., \& Turskis, Z. 2010. "Selection of rational dispute resolution method by applying new step-wise weight assessment ratio analysis (SWARA)." Journal of bBusiness Economics and Management, 11(2), 243-258.

Mavi, R.K., Goh, M., \& Zarbakhshnia, N. 2017. "Sustainable third-party reverse logistic provider selection with fuzzy SWARA and fuzzy MOORA in plastic industry." The International Journal of Advanced Manufacturing Technology, 91(5-8), 2401-2418. https://doi.org/10.1007/s00170-016-9880-x

Meade, L., \& Sarkis, J. 2002. "A conceptual model for selecting and evaluating third-party reverse logistics providers." Supply Chain Management: An International Journal, 7(5), 283-295. https://doi.org/10.1108/13598540210447728

Min, H., \& Ko, H.J. 2008. "The dynamic design of a reverse logistics network from the perspective of third-party logistics service providers." International Journal of Production Economics, 113(1), 176-192. https://doi.org/10.1016/j.ijpe.2007.01.017

Perçin, S. 2019. "An integrated fuzzy SWARA and fuzzy AD approach for outsourcing provider selection." Journal of Manufacturing Technology Management, 30(2), 531-552.

Prakash, C., \& Barua, M.K. 2016a. "An analysis of integrated robust hybrid model for third-party reverse logistics partner selection under fuzzy environment." Resources, Conservation and Recycling, 108, 63-81. https://doi.org/10.1016/j.resconrec.2015.12.011

Prakash, C., \& Barua, M.K. 2016b. "A combined MCDM approach for evaluation and selection of third-party reverse logistics partner for Indian electronics industry." Sustainable Production and Consumption, 7, 6678. https://doi.org/10.1016/j.spc.2016.04.001

Rogers, D. S., \& Tibben-Lembke, R. 2001. "An examination of reverse logistics practices.” Journal of Business Logistics, 22(2), 129-148. https://doi.org/10.1002/j.2158-1592.2001.tb00007.x

Saen, R.F. 2009. "A mathematical model for selecting third-party reverse logistics providers." International Journal of Procurement Management, 2(2), 180-190. https://doi.org/10.1504/IJPM.2009.023406 
Saen, R.F. 2010. "A new model for selecting third-party reverse logistics providers in the presence of multiple dual-role factors." The International Journal of Advanced Manufacturing Technology, 46(1-4), 405-410. https://doi.org/10.1007/s00170-009-2092-x

Sasikumar, P. \& Haq, A.N. 2011. "Integration of closed loop distribution supply chain network and 3PRLP selection for the case of battery recycling." International Journal of Production Research, 49(11), 33633385. https://doi.org/10.1080/00207541003794876

Senthil, S., Srirangacharyulu, B., \& Ramesh, A. 2014. "A robust hybrid multi-criteria decision making methodology for contractor evaluation and selection in third-party reverse logistics." Expert Systems with Applications, 41(1), 50-58. https://doi.org/10.1016/j.eswa.2013.07.010

Suyabatmaz, A.Ç., Altekin, F.T., \& Şahin, G. 2014. "Hybrid simulation-analytical modeling approaches for the reverse logistics network design of a third-party logistics provider.” Computers \& Industrial Engineering, 70, 74-89. https://doi.org/10.1016/j.cie.2014.01.004

Tavana, M., Zareinejad, M., Santos-Arteaga, F.J., \& Kaviani, M.A. 2016. “A conceptual analytic network model for evaluating and selecting third-party reverse logistics providers." The International Journal of Advanced Manufacturing Technology, 86(5-8), 1705-1721. https://doi.org/10.1007/s00170-015-8208-6

Xiangru, M. 2008. "Study of evaluation and selection on third party reverse logistics providers." In 2008 International Seminar on Business and Information Management (Vol. 1, pp. 518-521). IEEE.

Zarbakhshnia, N., Soleimani, H., \& Ghaderi, H. 2018. "Sustainable third-party reverse logistics provider evaluation and selection using fuzzy SWARA and developed fuzzy COPRAS in the presence of risk criteria." Applied Soft Computing, 65, 307-319.

Zarbakhshnia, N., Wu, Y., Govindan, K., \& Soleimani, H. 2020. "A novel hybrid multiple attribute decisionmaking approach for outsourcing sustainable reverse logistics.” Journal of Cleaner Production, 242, 118461. https://doi.org/10.1016/j.jclepro.2019.118461

Zhang, Y., \& Feng, Y. 2007. “A selection approach of reverse logistics provider based on fuzzy AHP.” In Fourth International Conference on Fuzzy Systems and Knowledge Discovery (FSKD 2007 August) (Vol. 3, pp. 479-482). IEEE.

Zikmund, W.G., \& Stanton, W.J. 1971. "Recycling solid wastes: a channels-of-distribution problem.” Journal of Marketing, 35(3), 34-39. https://doi.org/10.1177/002224297103500306 